\title{
Experimental Studies on the Nervous Control of the Renal Circulation
}

\section{Effect of the Electrical Stimulation of Splanchnic, Vagal and Other Somatic Nerves and of the Occlusion of Carotid Arteries on the Renal Circulation}

\author{
Jugoro TAKEUCHI, M.D., Eiichi UCHIDA, M.D., \\ Shosaku NAKAYAMA, M.D., Tadanao TAKEDA, M.D., \\ Shigeru YAGI, M.D., Gosuke Inoue, M.D., \\ and Hideo UEDA, M.D.
}

In order to investigate the nervous control of the renal circulation, the renal blood flow was measured by electromagnetic flow meter during the stimulation of the distal cut ends of the splanchnic nerves and the vagal nerve. In addition, the alterations of renal blood flow were observed on carotid occlusion and on stimulation of the proximal end of the divided femoral, sciatic and cervical vagal nerves. The stimulation of the greater and lesser splanchnic nerves produced constriction of renal vessels but the stimulation of the least splanchnic nerve had no effect. The effect of stimulation of the distal end of the vagal nerve to the renal vessels remained unestablished. Carotid occlusion did not influence the renal blood flow. The stimulation of the proximal end of the divided femoral or sciatic nerve may have produced renal vasoconstriction. By the stimulation of the proximal end of the divided vagal nerve, the renal vessels showed various responses with no relation to the alteration in blood pressure. It is a matter of interest that renal vasodilatation may take place in response to vagal afferent stimuli.

$\mathrm{I}^{\mathrm{T}}$ $\mathrm{T}$ has been well recognized anatomically that the kidney has an abundant supply of nerve fibers. In spite of vigorous efforts of many investigators, the functional facet of these nerves has not been clarified in details. Also it has not been established definitely whether the renal blood flow remains constant or is variable along with the alterations of systemic circulation in various conditions. It is a matter of interest and is still unknown what a role the nerves in the kidney play in physiologic regulation of renal hemodynamics. In the present study, alterations of renal

From the Second Department of Internal Medicine, Faculty of Medicine, University of Tokyo, Tokyo. 
blood flow by the electrical stimulation of the distal cut ends of the nerves which are distributed to the kidney such as splanchnic nerves and vagal nerve are investigated. In addition, changes in renal blood flow are observed under the systemic circulatory changes produced by occlusion of carotid arteries and by electrical stimulation of proximal ends of the vagal, femoral and sciatic nerves in order to clarify the nervous regulatory aspects of renal circulation.

\section{METHODS}

Experiments were performed on 15 adult mongrel dogs, weighing 8 to $13 \mathrm{Kg}$., fixed in the supine position and anesthetized with thiopental sodium (20 to 30 $\mathrm{mg} / \mathrm{Kg}$.). The systemic arterial pressure was continuously recorded by means of an electromanometer connected to the cannulated femoral artery. The renal blood flow was simultaneously recorded by electromagnetic flow meter which was inserted in a circuit between renal vein and femoral vein. The circuit was made extracorporeally with polyethylene tube, one end of which was inserted into the renal vein close to the kidney and the other into the femoral vein. Thus in this procedure, the direct measurement of the outflow from the renal vein was accomplished continuously throughout the experiment. The renal vascular resistance was calculated by the following equation:

$$
\begin{aligned}
& \text { Renal vascular resistance }=\frac{\text { mean arterial pressure }}{\text { renal blood flow }} \mathrm{mm} . \mathrm{Hg} / \mathrm{ml} . / \mathrm{min} . \\
& \text { Mean arterial pressure }=\text { diastolic pressure }+\frac{\text { pulse pressure }}{3}
\end{aligned}
$$

Operations were carried out with a great caution to avoid nerve damage. The ovarian or spermatic vein was ligated. In some experiments the contralateral renal vessels and bilateral adrenal veins were also ligated. The dogs were heparinized prior to closing the circuit to prevent the blood coagulation.

The nerve to be stimulated was prepared free from the surrounding structures carefully and the stem was cut and the peripheral or central ending was kept exposed. Silver electrodes were then placed on the nerve. Electrical stimulation was applied to the distal ends of the divided greater, lesser and least splanchnic nerve and of the divided vagal nerve, in addition to the central ends of the divided femoral, sciatic and vagal nerve. Especially when the splanchnic nerves and the subdiaphragmatic vagal nerve were stimulated, a small mass of semi-liquid paraffin was applied arround the stems to insulate them from the surroundings. The electrical stimuli consisted of rectangular voltage pulses, the duration of a spike was $1 \mathrm{msec}$., frequency of the pulses 3 to 100 cycles per second, and voltage 0.5 to 30 volts. Each stimulation was continued for 30 seconds.

The carotid occlusion was performed by clamping of bilateral common carotid arteries for 30 seconds.

\section{Results}

\section{Greater Splanchnic Nerve Stimulation-}

As can be seen in Fig. 1 and 2, electrical stimulation of the divided 


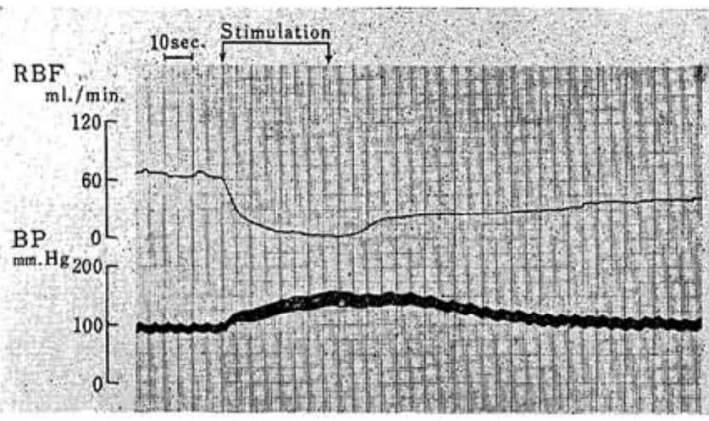

a.

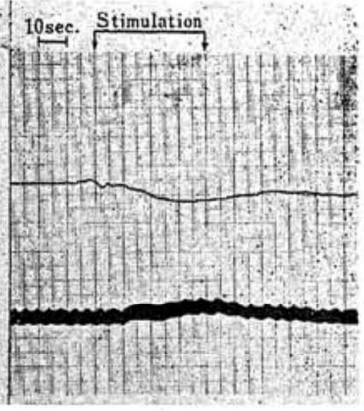

b.

Fig. 1. Dog No. 85 Adrenal veins not ligated.

a. Exp. 7 Stimulation of distal end of divided greater splanchnic nerve $(30 \mathrm{c} / \mathrm{s}, 5 \mathrm{~V})$.

b. Exp. 12 The same stimulation after intravenous injection of $10 \mathrm{mg}$. of regitine.

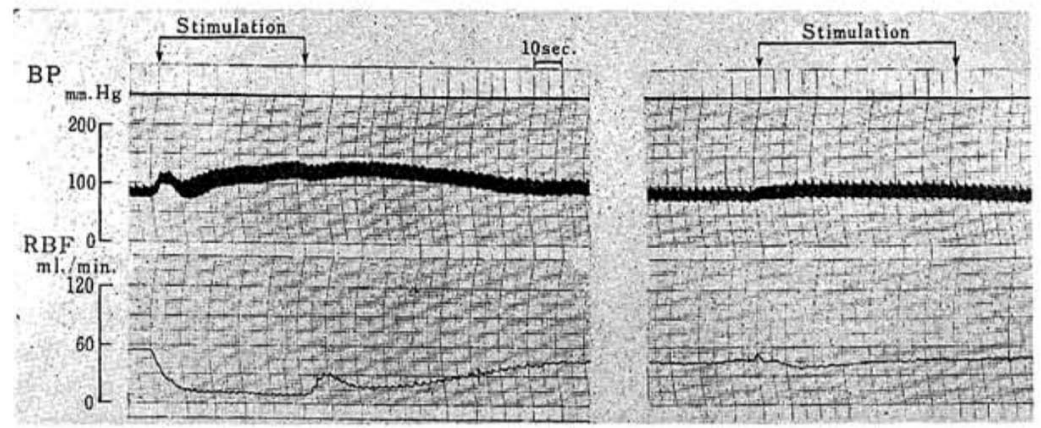

a.

b.

Fig. 2. Dog No.90 Bilateral adrenal veins were ligated.

a. Exp. 1 Stimulation of distal end of divided greater splanchnic nerve $(30 \mathrm{c} / \mathrm{s}, 3 \mathrm{~V})$.

b. Exp. 5 The same stimulation after intravenous injection of $1.2 \mathrm{mg}$. of hydergine.

greater splanchnic nerve on the distal end produced uniformly a rise in systemic arterial pressure and a simultaneous decrease in renal blood flow in all 23 experiments. The calculated renal vascular resistance increased markedly. The elevation of mean arterial pressure ranged from 8 to $66 \mathrm{~mm} . \mathrm{Hg}$ with an average of $26 \mathrm{~mm}$. $\mathrm{Hg}$ (10\% to $76 \%$, mean $35 \%)$. The decrease in renal blood flow was 15 to $82 \mathrm{ml} . / \mathrm{min}$. with a mean of $42 \mathrm{ml} . / \mathrm{min}$. (15\% to $97 \%$, mean $52 \%$ ). The change in renal vascular resistance was 2.1 to 48.6 times (mean 8.0 times) as high as the control level. On many occasions two phases could be distinguished in the pressor response; in the first phase (in 5 to $10 \mathrm{sec}$.) a rapid rise of blood pressure took place immediately after the onset of stimulation and then the pressure either came down shortly or was maintained at this elevated level; in the second 
phase (10 to $20 \mathrm{sec}$. later) the pressure rose more slowly again and maintained the high level until the release of stimulation. On the other hand, renal blood flow decreased abruptly and markedly with stimulation and changes in such two phases as observed in blood pressure responses were not recognized.

Lesser Splanchnic Nerve Stimulation-

Fig. 3 shows typical response to the stimulation of the lesser splanchnic

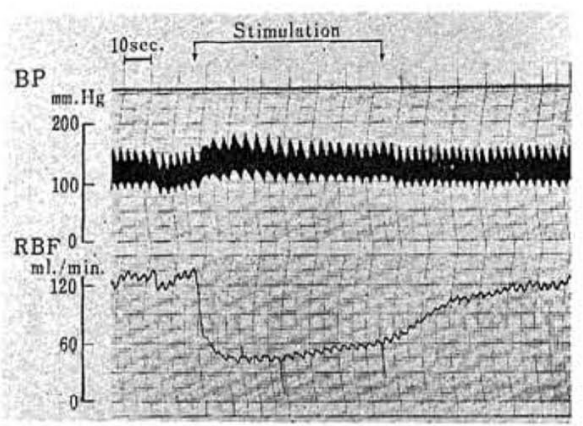

Fig. 3. Dog No. 82 Adrenal veins not ligated.

Exp. 4 Stimulation of distal end of divided lesser splanchnic nerve $(30 \mathrm{c} / \mathrm{s}, 7 \mathrm{~V})$.

nerve on the distal end. The systemic arterial pressure rose and the renal blood flow decreased markedly in 6 experiments on 2 dogs. The magnitude of hypertensive responses ranged from 9 to $31 \mathrm{~mm} . \mathrm{Hg}$ with a mean value of $18 \mathrm{~mm} . \mathrm{Hg}$ ( 7 to $27 \%$, mean $16 \%$ ), and the decrease in renal blood flow from 57 to $111 \mathrm{ml} . / \mathrm{min}$. with a mean of $80 \mathrm{ml} . / \mathrm{min}$. (43 to $84 \%$, mean $69.1 \%$ ). The renal vascular resistance was 1.8 to 6.7 times (mean 4.5 times) as high as the control level. The pressor response did not show any twophase pattern as seen in the greater splanchnic nerve stimulation.

\section{Least Splanchnic Nerve Stimulation-}

With the stimulation of the least splanchnic nerve in 4 dogs, neither constant nor significant responses of both systemic arterial pressure and renal blood flow were observed.

In the experiments of the greater or lesser splanchnic nerve stimulation, it was apparent that the elevation in blood pressure and the fall in renal blood flow were more striking as the stimulation became stronger in voltage within the range of 1 to 10 volts. There was no difference in the responses whether the adrenal veins of the dog were ligated or not (Fig. 1 and 2), and also whether the dog was vagotomized or not. These responses to the splanchnic nerve stimulation were inhibited or depressed after intravenous injection of $10 \mathrm{mg}$. of regitine ${ }^{\circledR}$ (Fig. 1) or 0.3 to $1.2 \mathrm{mg}$. of hydergine ${ }^{\circledR}$ (Fig. 1 and 2). 


\section{Efferent Vagal Nerve Stimulation-}

Stimulation of the distal end of the divided cervical vagus produced a prompt fall in blood pressure with cardiac arrest or bradycardia and a

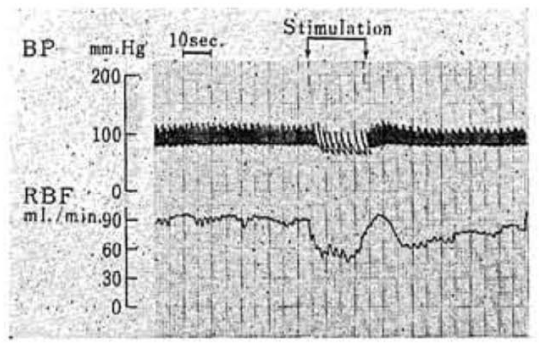

Fig. 4. Dog No. 84

Exp. 14. Stimulation of distal end of divided cervical vagal nerve $(5 \mathrm{c} / \mathrm{s}, 3 \mathrm{~V})$.

decrease in renal blood flow in all 12 experiments on 6 dogs (Fig. 4). The renal blood flow began to recover during stimulation in spite of persistence of the fall in blood pressure, and it decreased again after release of the stimulation, later slowly recovering to the value before the stimulation.

Subdiaphragmatic vagal nerve was stimulated on the distal end in 8 experiments on one dog. The less hypotensive response without bradycardia or cardiac arrest and less decreased renal blood flow were observed. The changes of the calculated renal vascular resistance were not significant (Fig. 5).

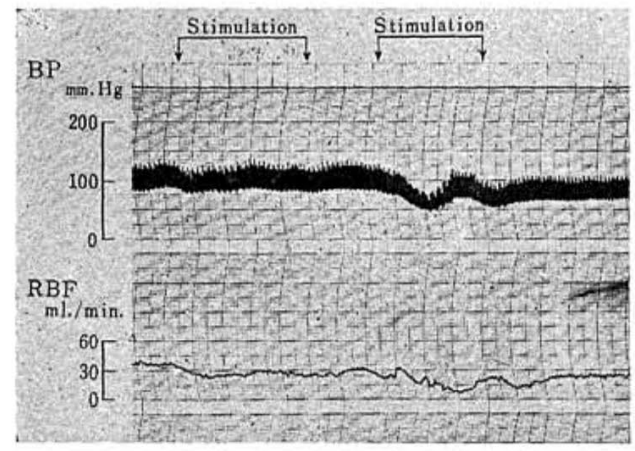

Fig. 5. Dog No. 81

Exp. 2. Stimulation of distal end of divided subdiaphragmatic vagal nerve $(30 \mathrm{c} / \mathrm{s}, 5 \mathrm{~V})$.

Exp. 3. Stimulation of distal end of divided subdiaphragmatic vagal nerve $(30 \mathrm{c} / \mathrm{s}, 10 \mathrm{~V})$.

\section{Carotid Occlusion-}

In 7 experiments on 4 dogs which showed 10 to $24 \mathrm{~mm} . \mathrm{Hg}$ rise in ' systemic blood pressure by the occlusion of common carotid arteries; the 
alterations in renal blood flow were not significant in all experiments $(-5$

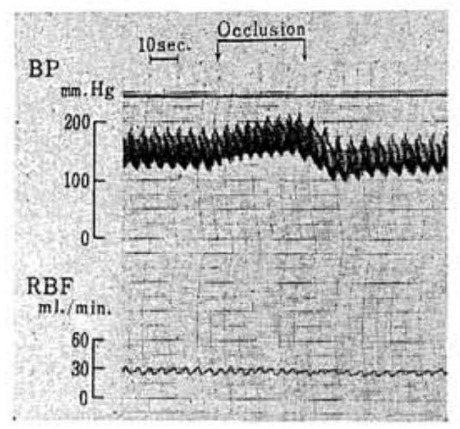

Fig. 6. Dog No. 105

Exp. 17 Occlusion of bilateral common carotid arteries.

to $+2 \mathrm{ml} . / \mathrm{min}$.). Fig. 6 shows such an example. The renal vascular resistance increased slightly in all cases. The rate of increase ranged from 7.4 to $18.1 \%$ with an average of $12.2 \%$.

\section{Afferent Stimulation of Femoral or Sciatic Nerve-}

By stimulating proximal end of the divided femoral or sciatic nerve in 10 dogs caused either hypertensive or hypotensive response. The renal blood flow decreased more or less in either response in blood pressure.

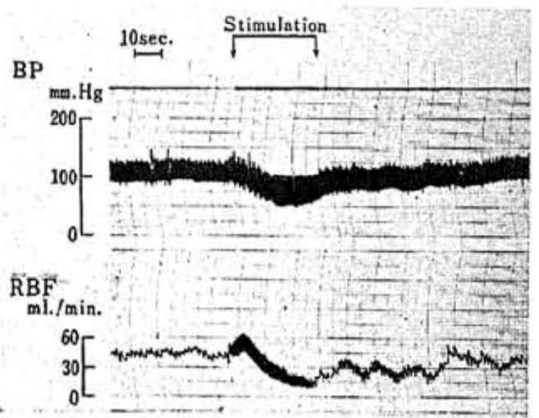

Fig. 7. Dog No. 102

Exp. 1 Stimulation of proximal end of divided femoral nerve $(50 \mathrm{c} / \mathrm{s}, 3 \mathrm{~V})$.

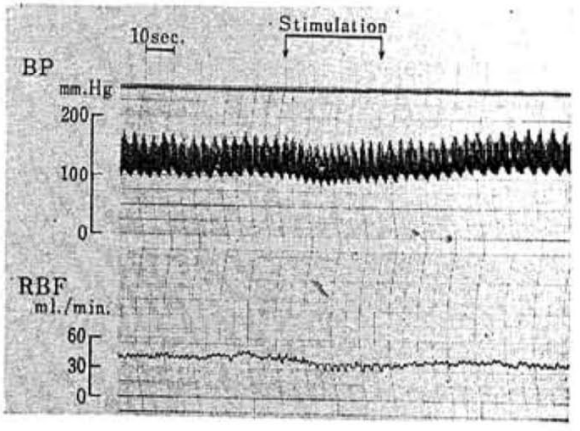

Fig. 8. Dog No. 105

Exp. 13 Stimulation of proximal end of divided sciatic nerve $(50 \mathrm{c} / \mathrm{s}, 20 \mathrm{~V})$.

Fig. 7 and 8 show a decrease in renal blood flow accompanied by hypotensive response, in femoral and sciatic nerve stimulation respectively. Fig. 9 is an example which showed a decrease in renal blood flow with hypertensive response. The response was hypertensive $(7$ to $22 \mathrm{~mm} . \mathrm{Hg})$ in 10 experiments and hypotensive $(7$ to $36 \mathrm{~mm}$. $\mathrm{Hg}$ ) in 12 cases. No essential difference was found between the stimulations of the femoral and sciatic nerve. In 4 dogs, high voltage stimulation produced hypertensive response 


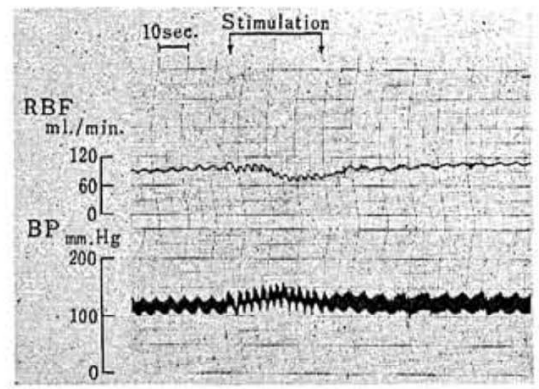

Fig. 9. Dog No. 109

Exp. 4 Stimulation of proximal end of divided sciatic nerve $(50 \mathrm{c} / \mathrm{s}, 20 \mathrm{~V})$.

and low voltage stimulation produced hypotensive response, whereas in 2 dogs response was always hypertensive and in 4 dogs hypotensive in any applied conditions. In addition, it was observed in hypertensive response that the elevation in blood pressure was produced more strikingly by the stimulation with higher voltage.

The decrease in renal blood flow was variable, maximum of $32 \mathrm{ml} . / \mathrm{min}$. (56.1\%) to minimum of $3 \mathrm{ml} . / \mathrm{min}$. $(6.1 \%)$, and generally slight in degree (mean: $10 \mathrm{ml} . / \mathrm{min} ., 23.8 \%$ ). In 5 of 8 experiments with femoral nerve stimulation and in 8 of 14 experiments with sciatic stimulation significant alterations in renal blood flow (over $8 \mathrm{ml} / \mathrm{min}$.) were recorded. In 9 experiments, the renal blood flow did not show any significant change in spite of alteration of the blood pressure.

The renal vascular resistance increased significantly in 13 experiments. The rate of increase ranged from 20 to $140 \%$ with an average of $38.4 \%$. Even in hypotensive response, the calculated vascular resistance was increased. As a rule, the fall in renal blood flow and the rise in renal vascular resistance were more striking as stimulation became stronger in voltage.

Afferent Cervical Vagal Nerve Stimulation-

By stimulating the proximal end of divided cervical vagal nerve, pressor, depressor or biphasic response occurred. Four dogs showed only hypotensive or only hypertensive response in any condition of stimulation and 3 dogs showed hypotensive response in low voltage and hypertensive response in high voltage.

The renal blood flow also varied and its change was not always related to the change in blood pressure. Fig. 10 shows the biphasic response in renal blood flow associated with hypertensive response. Fig. 11 is an example of increased renal blood flow with hypotensive response. Fig. 12 shows a decrease in renal blood flow accompanied by hypotensive response. In 17 experiments with hypertensive responses ranging from 11 to $55 \mathrm{~mm}$. Hg (mean $21 \mathrm{~mm} . \mathrm{Hg}, 30.8 \%$ ), the renal blood flow increased by 3 to $27 \mathrm{ml} . / \mathrm{min}$. with an average of $8.9 \mathrm{ml} . / \mathrm{min}$. (23.8\%) in all but 2 cases 


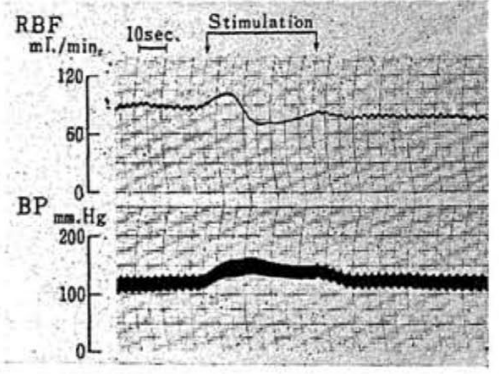

Fig. 10. Dog No. 109

Exp. 15 Stimulation of proximal end of divided cervical vagal nerve $(50 \mathrm{c} / \mathrm{s}, 30 \mathrm{~V})$.

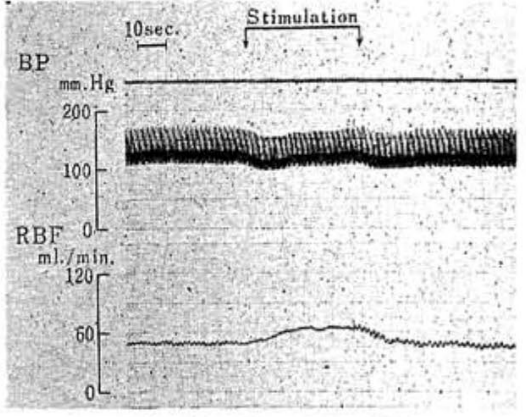

Fig. 11. Dog No. 108

Exp. 7 Stimulation of proximal end of divided cervical vagal nerve $(100 \mathrm{c} / \mathrm{s}, 20 \mathrm{~V})$.

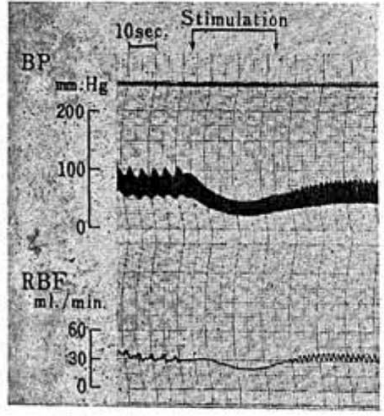

Fig. 12. Dog No. 105

Exp. 8 Stimulation of proximal end of divided cervical vagal nerve $(50 \mathrm{c} / \mathrm{s}, 15 \mathrm{~V})$.

with biphasic changes. In only 9 experiments, however, these changes were significant. In 16 experiments with hypotensive responses ranging from 9 to $43 \mathrm{~mm} . \mathrm{Hg}$ (mean $17 \mathrm{~mm} . \mathrm{Hg}, 22.9 \%$ ) the renal blood flow increased in 6 (mean $13 \mathrm{ml} . / \mathrm{min} ., 31.6 \%$ ) and decreased in 4 (mean $8 \mathrm{ml} . / \mathrm{min} ., 22 \%$ ). In the remainder it did not change significantly. One biphasic response in blood pressure was accompanied by a biphasic change in renal blood flow.

The changes in renal vascular resistance were much variable and had no relation to the alterations in blood pressure. The renal vascular resistance increased in 6 , decreased in 2, did not change in 9 cases with hypertensive response and increased in 2, decreased in 11, did not change in 3 with hypotensive response and did not change in a case with biphasic response in blood pressure. It could not be found in this study, that the changes in renal blood flow and in renal vascular resistance had any relation to the voltage or to the frequency of the stimulant pulses. 


\section{Discussion}

The regulation of renal circulation is carried out by nervous and hormonal control as well as by autoregulatory mechanism. The kidney is supplied with nerves mainly by the way of the renal plexus communicated with the greater and lesser splanchnic nerves and the vagal nerve., ${ }^{1,2}$

On the effect of direct renal nerve stimulation, Study and Shipley ${ }^{3)}$ reported $53 \%$ average decrease in renal blood flow measured by a rotameter. Houck $^{4}$ observed reduction in renal blood flow, glomerular filtration rate and urine flow. On the effect of splanchnic nerves, Nakayama, ${ }^{\text {s }}$ one of authors, also reported a decrease in renal blood flow and glomerular filtration rate with an average of $88.4 \%$ and $86.3 \%$ respectively, by the methods of renal clearance, renal vein catheterization and renal vein cannulation. In the present study the greater, the lesser and the least splanchnic nerves were stimulated separately, to observe the difference of renal innervation among these nerves. For the alterations of systemic arterial pressure, the stimulation of the greater splanchnic nerve was the most effective, that of the lesser splanchnic nerve was less, and of the least splanchnic nerve not effective. On the effect to renal blood flow, the stimulation of the greater splanchnic nerve decreased it as markedly as the lesser splanchnic nerve, although the least splanchnic nerve had no significant effect. These results suggest that the greater splanchnic nerve has more wide distribution of its nerve endings to vascular beds including the kidney than the lesser splanchnic nerve which has a distribution relatively confined to the kidney and the least splanchnic nerve supplies scarecely vasoconstrictive fibers to the kidney. The decrement of 52 or $69.1 \%$ in renal blood flow in our electromagnetic flow meter method was in complete accordance with the $53 \%$ decrease in rotameter method reported by Study and Shipley. ${ }^{3 \prime}$ These effects of splanchnic nerve stimulation were not influenced by ligation of the adrenal veins. This indicates that the responses to stimulation of splanchnic nerves were produced rather directly by neural than hormonal effect. Regitine and hydergine depressed or inhibited the effect of the splanchnic nerve stimulation and vascodilatatory effect by stimulation of splanchnic nerves could not be observed even after an injection of such adrenolytic substances.

It has been demonstrated anatomically that vagal nerve is distributed in the kidney ${ }^{2}$ ) but its role in renal circulatory regulation is not quite clear. Burton-Opitz and Lucas ${ }^{\text {() }}$ concluded in their report that the vagi do not embrace nerve fibers by means of which the vascularity of the kidney may be altered. In our study, the renal blood flow was markedly reduced with hypotensive response and bradycardia by the distal stimulation of the divided vagal nerve of the cervical portion. Its change is considered to be mainly due to decrease in cardiac output. But, further, 
even in the distal stimulation of vagal nerve amputated at the subdiaphragmatic portion to avoid the cardiac effect, systemic arterial pressure fell and renal blood flow decreased. It could not be concluded yet because the results were obtained in only one dog with subdiaphragmatic vagal nerve stimulation and the changes in calculated renal vascular resistance were not significant.

Many authors have described that the renal blood flow remains constant while systemic arterial pressure alters whithin a physiological range. ${ }^{7}$ To study whether renal blood flow is maintained at a constant level or not in various conditions, electrical stimuli on the proximal ends of divided sciatic, femoral and vagal nerves and carotid occlusion were applied in this study.

In carotid sinus reflex, Heymans ${ }^{81}$ found a decrease and Kigawa ${ }^{91}$ observed a slight increase in renal blood flow. On the other hand, the curious independence of the renal blood flow was reported in hypertensive response by $\operatorname{Rein}^{10}$ and was also observed in hypotensive response by Opitz and Smith. ${ }^{11}$ Unna ${ }^{12}$ described no detectable influence on the renal blood flow in hypertensive response due to clamping both carotids and in hypotensive response due to distension of one carotid sinus. In our study, in hypertensive response to carotid occlusion, the renal blood flow did not alter as Rein reported. The calculated renal vascular resistance increased slightly. Engelhorn ${ }^{13), 16)}$ described that nerve impulse obtained from renal nerve in cats increases with elevation in blood pressure by carotid occlusion. Therefore, it is considered that in carotid occlusion renal vessels may constrict so slightly by neural control as renal blood flow shows no change.

During the stimulation of the central ends of the sciatic nerve, Roy ${ }^{15}$, and Bradford ${ }^{16)}$ observed well-marked contraction of kidney by oncometric records. Recently, Kigawa ${ }^{9)}$ reported that the renal blood flow decreased in most of the experiments with hypertensive response and its decrement was greater in higher voltage stimulation by the method of electromagnetic flow meter. Burton-Opitz and Lucas, ${ }^{6)}$ however, described that the renal blood flow remains practically unaltered by measurement of thermostromuhr. In this study by electromagnetic flow meter measurement, the renal blood flow did not change or decreased and the renal vascular resistance increased in either hypertensive or hypotensive response to the stimulation of proximal ends of femoral or sciatic nerve. It should be noted that the change in renal blood flow is not directly related to the alteration in blood pressure but is related to voltage of applied stimulation. This fact indicates that in the stimulation of central femoral or sciatic nerve the renal blood flow is influenced by a neuro-reflexive effect, probably mediated by the central nervous system such as spinal cord, rather than by alterations in systemic arterial pressure and the attitude of renal 
vascular vessels attributes little to elevation or reducation in blood pressure.

On the effect of the stimulation of the afferent cervical vagal nerve on renal blood flow, Bradford described that the kidney volume decreased by stimulation of this nerve. Burton-Opitz ${ }^{6)}$ observed that no change in renal blood flow occurred even at a time when the very pronounced rises in arterial blood pressure had fully developed. By Kigawa ${ }^{\prime \prime}$ the alteration in renal blood flow was indicated to be various, though the hypertensive response was generally accompanied by the renal vasoconstriction. Quite various results in blood pressure and in renal blood flow were obtained in this study. The renal blood flow remained unaltered in 14 of 33 experiments in spite of the change in blood pressure. When any change in renal blood flow was observed, the renal blood flow was not always related to the blood pressure. In hypertensive responses, the renal blood flow usually increased but in hypotensive responses the change in renal blood flow was various. Also the calculated renal vascular resistance was various and not related to the blood pressure. The alterations of renal blood flow and renal vascular resistance were independent of the conditions of stimulation such as voltage and frequency. This result is different from that of the afferent stimulation of femoral or sciatic nerve.

It is of interest that in some hypotensive responses the renal blood flow increased and the renal vascular resistance was reduced. This fact suggests that the afferent stimulation of the vagal nerve may produce vasodilatation in renal vessels.

Although carotid occlusion, the afferent stimulation of the divided vagal, and femoral or sciatic nerves were applied in order to observe the changes in renal blood flow in the alterations of systemic arterial pressure, it was apparent that obtained results could not be discussed uniformly because these procedures might have some specific influences, if any, to the renal vessels. It is, however, not clear what a mechnism produces such specific effects.

\section{SumMary}

By means of electromagnetic flow meter the alterations of renal blood flow were observed in dogs in various conditions, to study nervous control of renal circulation, and following results were obtained.

(1) In electrical stimulation of the distal end of the divided greater and lesser splanchnic nerves, the systemic blood pressure rose and the renal blood flow decreased.

(2) In stimulation of the distal end of the divided least splanchnic nerve, no change in blood pressure and in renal blood flow was observed.

(3) In stimulation of the distal end of the divided cervical vagal nerve, the renal blood flow decreased with bradycardia or cardiac arrest. 
In stimulation of the subdiaphragmatic portion, the blood pressure fell and the renal blood flow decreased slightly.

(4) In hypertensive response due to the occlusion of common carotid arteries, the renal blood flow did not change.

(5) In stimulation of the proximal end of the divided femoral or sciatic nerve, the renal blood flow did not change or decreased in either hypertensive or hypotensive response.

(6) In stimulation of the proximal end of the divided cervical vagal nerve, changes in blood pressure and in renal blood flow were various. The alteration of renal blood flow was related neither to the change in blood pressure nor to the conditions of stimulation.

\section{ACKNOWLEDGEMENT}

The authors wish to express their thanks to Mr. S. Ushiama for his excellent technical assistance throughout this experiment.

\section{REFERENCES}

1. Smith, L.H.: The Kidney: Structure and Function in Health and Disease. Oxford University Press, Inc., New York. 1951.

2. Gruber, C. M.: Physiol. Rev. 13: 497, 1933.

3. Study, R.S. and Shipley, R. E. : Am. J. Physiol. 163: 442, 1950.

4. Houck, C. R.: Am. J. Physiol. 167: 523, 1951.

5. Nakayama, S.: Respiration and Circulation 7: 55, 1959 (In Japanese).

6. Burton-Opitz and Lucas, D.R.: J. Exp. Med. 13: 308, 1911.

7. Winton, F.R.: Physiol. Rev. 17: 408, 1937.

8. Heymans, C., et al.: Arch Int. Pharmacodyn. $40: 292,1931$.

9. Kigawa, Y.: Jap. J. Nephrology 2: 541, 1960 (In Japanese).

10. Rein, H., et al.: Pflügers Arch. Physiol. 238: 239, 1937.

1. Opitz, E. and Smyth, D. H.: Pflügers Arch. Physiol. 238 : 633, 1937.

12. Unna, K.: Pflügers Arch. Physiol. $235:$ 513, 1935.

13. Engelhorn, R.: Arch. f. exper. Path. u. Pharmakol. 231: 217, 1957.

14. Engelhorn, R.: Arch. f. exper. Path. u. Pharmakol. 232: 251, 1957.

15. Roy, S., et al.: Virchows Arch. f. Path. Anat. 17: 424, 1883.

16. Bradford, J. R.: J. Physiol. 23 : 415. 1899. 